\title{
Siriraj stroke score and validation study to distinguish supratentorial intracerebral haemorrhage from infarction
}

\author{
Niphon Poungvarin, Adulya Viriyavejakul, Chulaluk Komontri
}

\begin{abstract}
Objectives-To develop a simple, reliable, and safe diagnostic tool for acute stroke syndromes in a setting where computerised brain scanning was not readily available and to validate its accuracy with regard to pathological types of stroke.

Design-13 clinical variables that potentially might differentiate supratentorial cerebral haemorrhage from infarction were recorded and tested by multivariate analysis in a prospective study of 174 patients with acute stroke. In developing the Siriraj stroke score stepwise discriminant analysis of the variables was followed by a linear discriminant equation to differentiate between supratentorial haemorrhage and infarction. The score obtained was validated against scores in 206 other patients with stroke, computerised brain scans being used for definitive diagnosis.
\end{abstract}

Setting-Siriraj Hospital Medical School, Mahidol University, Bangkok.

Subjects-Prospective study: 174 consecutive patients with acute supratentorial stroke syndrome (not subarachnoid haemorrhage) admitted to Siriraj Hospital during 1984-5; validation study: 206 patients admitted to Siriraj Hospital or another hospital for supratentorial intracerebral haemorrhage or infarction.

Results-The Siriraj stroke score was developed and calculated as $(2.5 \times$ level of consciousness $)+$ $(2 \times$ vomiting $)+(2 \times$ headache $)+(0 \cdot 1 \times$ diastolic blood pressure $)-(3 \times$ atheroma markers $)-12$. A score above 1 indicates supratentorial intracerebral haemorrhage, while a score below -1 indicates infarction. The score between 1 and -1 represents an equivocal result needing a computerised brain scan or probability curve to verify the diagnosis. In the validation study of the Siriraj stroke score the diagnostic sensitivities of the score for cerebral haemorrhage and cerebral infarction were $89.3 \%$ and $93.2 \%$ respectively, with an overall predictive accuracy of $90 \cdot 3 \%$.

Conclusion-The Siriraj stroke score is widely

Department of Medicine, Faculty of Medicine, Siriraj Hospital, Mahidol

University, Bangkok 10700, Thailand

Niphon Poungvarin, FRCP, associate professor of neurology Adulya Viriyavejakul, FRCP, associate professor of neurology Chulaluk Komontri, MSC, statistician, clinical epidemiology unit

Correspondence to: Professor Poungvarin, Division of Neurology.

BMJ 1991;302:1565-7 accepted and applied in hospitals throughout Thailand as a simple and reliable bedside method for diagnosing acute stroke.

\section{Introduction}

Developing countries like Thailand have been burdened not only with infectious diseases but also with non-communicable diseases such as diabetes mellitus, hypertension, heart disease, stroke, and cancer. With highly refined technologies becoming increasingly available worldwide physicians must be selective in applying these to patients. The cost constraint is greater in developing countries. Investigative procedures in neurology, notably computerised brain scanning and magnetic resonance imaging, are prohibitively expensive in both the initial investment and the maintenance, requiring careful consideration in their acquisition and usage.

Stroke is the commonest problem among neurological inpatients encountered at Siriraj Hospital Medical School, Bangkok. ${ }^{1}$ Each year some 500 new patients with acute stroke are admitted. Proper management of the acute stroke syndrome is based on the correct diagnosis of its pathological type. Computed brain tomography is an accurate, safe, and $\vec{F}$ non-invasive procedure for differentiating between $\mathcal{O}$ cerebral haemorrhage and infarction. In Thailand, 은 however, this facility is not available countrywide. N Physicians in charge of acute stroke have therefore to resort to the usual routine procedures in conjunction with clinical features, which have been shown to be unreliable. $^{2-5}$

The aims of this study were twofold: to attempt to improve accuracy in diagnosing the acute stroke 0 syndrome based on clinical variables at the bedside; and to develop a simple, reliable, and safe diagnostic model as compared with other, highly elaborate instruments in biomedical sciences. As a result a stroke score card-the Siriraj stroke score-was developed and has been used throughout Thailand since 1986 . The validation study of the score was carried out in different groups of patients with the disease in order to verify its accuracy.

\section{Patients and methods} PROSPECTIVE STUDY

One hundred and seventy four consecutive patients with acute supratentorial stroke syndrome (excluding subarachnoid haemorrhage) admitted to Siriraj 윽 Hospital during 1984-5 were enrolled in the study. N Patients were diagnosed by using the World Health Organisation's criteria for the acute stroke syndrome - 음 namely, rapid onset of clinical signs of focal or global disturbance of cerebral function lasting more than 24 hours or leading to death with no apparent cause $\omega$ other than a vascular lesion. Clinical variables potentially useful in differentiating cerebral infarction and 6 haemorrhage were recorded on admission. These were $\overparen{\Phi}$ age, sex, loss of consciousness at onset, level of consciousness, headache, vomiting, diastolic blood pressure, signs of meningël irritation, plantar reflex $\underset{\mathbb{D}}{ }$ response, atheroma markers, history of hypertension, previous stroke event, and underlying heart disease.

The clinical variables were scored as follows. Level of consciousness was scored as alert (zero), drowsy or $\delta$ stuporous (1 point), and semicomatose or comatose ( 2 points). History of headache within two hours of onset and history of vomiting after onset each scored $\rightleftharpoons$ 1 point. Atheroma markers were classified as a history of diabetes, angina, or intermittent claudication. The patient scored 1 point if he or she had one or more atheroma markers. Meningeal signs, abnormal plantar 
reflex, history of hypertension, previous stroke event, and underlying heart disease were each scored 1 point if present. A zero score was assigned in the absence of any history or physical findings of the listed variables. Whenever the occurrence of a symptom was not clear it was recorded as absent and scored zero.

To obtain a definite diagnosis of haemorrhage or infarction all patients had a computerised brain scan performed within the first 72 hours of the onset of stroke. The computerised brain scanner was the General Electric CT/T 8000/8800 system.

Statistical methods - All data analyses were done with the statistical package for the social sciences (SPSS). Initially $\chi^{2}$ and $t$ tests were applied to each of the 13 clinical variables to test for significance between haemorrhage and infarction. Stepwise multiple discriminant analysis then yielded a linear discriminant equation showing the relation between the discriminant score and the independent variables. The linear discriminant equation may be written as: $\mathrm{D}=\mathrm{a}+\mathrm{b}_{1} \mathrm{X}_{1}+\mathrm{b}_{2} \mathrm{X}_{2}+. . .+\mathrm{b}_{\mathrm{p}} \mathrm{X}_{\mathrm{p}}$, where $\mathrm{D}=$ dis criminate score, $a=$ constant, $b_{i}=$ discriminant coefficient $(\mathrm{i}=1,2, \ldots \mathrm{p})$, and $\mathrm{X}_{\mathrm{i}}=$ independent variable. $\mathrm{D}$ was labelled as the Siriraj stroke score, and cards bearing the Siriraj stroke score have been distributed to hospitals throughout Thailand.

\section{VALIDATION STUDY}

For the validation study of the Siriraj stroke score the linear discriminant equation was applied to a second set of patients who suffered supratentorial intracerebral haemorrhage or infarction. The cut off point of the discriminant score was previously identified in the prospective study by choosing the best separation - that is, the highest accuracy-between the two groups.

Validating the Siriraj stroke score began two years after the score cards had been applied to patients with acute stroke in the Thai population. In this study 206 patients with acute supratentorial stroke from Thonburi Hospital and Siriraj Hospital were examined

TABLE I-Analysis of 13 variables that might differentiate cerebral infarction from haemorrhage. Except where stated otherwise figures are numbers (percentages) of patients ${ }^{\star}$

\begin{tabular}{|c|c|c|c|}
\hline & $\begin{array}{l}\text { Patients with haemorrhage } \\
\qquad(\mathbf{n}=75)\end{array}$ & $\begin{array}{l}\text { Patients with infarction } \\
\qquad(\mathrm{n}=99)\end{array}$ & $\mathrm{p}$ Value \\
\hline (1) Mean age (years) (SD) & $59 \cdot 84(13.04)$ & $60 \cdot 83(14 \cdot 31)$ & 0.640 \\
\hline \multirow{2}{*}{\multicolumn{4}{|c|}{ (3) Sex: }} \\
\hline & & & \\
\hline $\begin{array}{l}\text { Male } \\
\text { Female }\end{array}$ & $\begin{array}{l}36(48 \cdot 0) \\
39(52 \cdot 0)\end{array}$ & $\left.\begin{array}{l}50(50 \cdot 5) \\
49(49 \cdot 5)\end{array}\right\}$ & \multirow[t]{2}{*}{$0 \cdot 8617$} \\
\hline \multicolumn{3}{|l|}{$\begin{array}{l}\text { Female } \\
\text { (4) Loss of consciousness at onset? }\end{array}$} & \\
\hline $\begin{array}{l}\text { No } \\
\text { Yes }\end{array}$ & $\begin{array}{l}40(53 \cdot 3) \\
35(46 \cdot 7)\end{array}$ & $\left.\begin{array}{l}81(81 \cdot 8) \\
18(18 \cdot 2)\end{array}\right\}$ & 0.0001 \\
\hline \multicolumn{4}{|l|}{ (5) Headache within two hours of onset? } \\
\hline No & $43(60 \cdot 6)$ & $80(84 \cdot 2)\}$ & \multirow{2}{*}{0.0011} \\
\hline \multicolumn{3}{|l|}{ (6) Vomiting? } & \\
\hline $\begin{array}{l}\text { No } \\
\text { Yes }\end{array}$ & $\begin{array}{l}40(54 \cdot 8) \\
33(45 \cdot 2)\end{array}$ & $\left.\begin{array}{l}82(86 \cdot 3) \\
13(13 \cdot 7)\end{array}\right\}$ & \multirow[t]{2}{*}{$<0.0001$} \\
\hline \multicolumn{3}{|l|}{ (7) Meningeal signs? } & \\
\hline No & $60(81 \cdot 1)$ & $96(97 \cdot 0)\}$ & \multirow{2}{*}{0.0013} \\
\hline Yes & $14(18 \cdot 9)$ & $3(3.0)\}$ & \\
\hline \multicolumn{4}{|l|}{ (8) Level of consciousness: } \\
\hline Alert & $16(21 \cdot 3)$ & $58(58 \cdot 6)$ & \multirow{3}{*}{$<0.0001$} \\
\hline Drowsy, stupor & $33(44 \cdot 0)$ & $31(31 \cdot 3)\}$ & \\
\hline Semicoma, coma & $26(34 \cdot 7)$ & $10(10 \cdot 1)$ & \\
\hline \multicolumn{4}{|l|}{ (9) Plantar responses: } \\
\hline No response & $14(19 \cdot 2)$ & $10(10 \cdot 3)$ & \multirow{4}{*}{0.0516} \\
\hline Both flexor & $8(11 \cdot 0)$ & $24(24 \cdot 8)$ & \\
\hline Single extensor & $39(53.4)$ & $53(54 \cdot 6)$ & \\
\hline Both extensor & $12(16 \cdot 4)$ & $10(10 \cdot 3)]$ & \\
\hline \multicolumn{4}{|l|}{ (10) Atheroma markers: } \\
\hline None & $70(93 \cdot 3)$ & $69(69 \cdot 7)\}$ & \multirow{2}{*}{0.0003} \\
\hline \multicolumn{3}{|l|}{ (11) History of hypertension? } & \\
\hline No & $28(37 \cdot 3)$ & $41(41 \cdot 4)\}$ & \multirow{2}{*}{0.6977} \\
\hline Yes & $47(62 \cdot 7)$ & $58(58 \cdot 6)\}$ & \\
\hline \multicolumn{4}{|l|}{ (12) Previous stroke event? } \\
\hline No & $63(84 \cdot 0)$ & $85(85 \cdot 9)\}$ & \multirow{2}{*}{0.8998} \\
\hline $\begin{array}{l}\text { Yes } \\
\text { (13) Underlying heart disease? }\end{array}$ & $12(16 \cdot 0)$ & $14(14 \cdot 1)\}$ & \\
\hline \multicolumn{4}{|l|}{ (13) Underlying heart disease? } \\
\hline $\begin{array}{l}\text { No } \\
\text { Yes }\end{array}$ & $\begin{array}{l}27(38 \cdot 0) \\
44(62 \cdot 0)\end{array}$ & $\begin{array}{l}\left.\begin{array}{l}43(43 \cdot 9) \\
55(56 \cdot 1)\end{array}\right\}\end{array}$ & $0 \cdot 5460$ \\
\hline
\end{tabular}

*In a few cases in both groups some variables were not recorded.
TABLE II - Validation study of Siriraj stroke score

\begin{tabular}{ccc}
\hline Siriraj stroke score & $\begin{array}{c}\text { Patients with haemorrhage } \\
(\mathbf{n}=142)\end{array}$ & $\begin{array}{c}\text { Patients with infarction } \\
(\mathbf{n}=64)\end{array}$ \\
\hline Below -1 & 13 & 41 \\
$-1,1$ & 21 & 20 \\
Above 1 & 108 & 3
\end{tabular}

Sensitivity for haemorrhage (score above 1): 108/121 $=89 \cdot 3 \%$ (confidence interval $83 \cdot 8 \%$ to $94 \cdot 8 \%$ )

Sensitivity for infarction (score below -1 ): $41 / 44=93 \cdot 2 \%$ (confidence interval $85.8 \%$ to $100 \cdot 6 \%$ )

Accuracy: $149 / 165=90 \cdot 3 \%$

\begin{tabular}{l} 
Original version \\
$\quad$ Siriraj stroke score $=(0.80 \times$ consciousness $)+(0.66 \times$ vomiting $)$ \\
$+(0.66 \times$ headache $)+(0.03 \times$ diastolic blood pressure $)$ \\
$\quad-(0.99 \times$ atheroma $)-371$ \\
Simplified version \\
$\quad$ Siriraj stroke score $=(2.5 \times$ consciousness $)+(2 \times$ vomiting $)+$ \\
$(2 \times$ headache $)+(0.1 \times$ diastolic blood pressure $)-(3 \times$ atheroma $)-12$ \\
\hline Consciousness: alert $=0$; drowsy, stupor $=1 ;$ semicoma, coma $=2$ \\
Vomiting: $n=0 ;$ yes $=1$ \\
Headache within two hours: no $=0 ;$ yes $=1$ \\
Atheroma markers: none $=0 ;$ one or more $=1$
\end{tabular}

FIG 1-Details of Siriraj stroke score

by two clinicians who had been asked to make a diagnosis of either infarction or haemorrhage based on the Siriraj stroke score. A score above 1 was classified as cerebral haemorrhage whereas a score below -1 was classified as cerebral infarction. The outcome of computerised brain scanning was not known to them. The results were then compared, computerised brain scanning being used for definitive diagnosis in order to determine the accuracy of the Siriraj stroke score.

\section{Results}

PROSPECTIVE STUDY

Of the 174 patients with the acute stroke syndrome who had computerised brain scanning performed, supratentorial cerebral haemorrhage was confirmed in 75 and infarction in 99 . An initial univariate analysis was made of the 13 clinical variables recorded on admission that potentially might differentiate between the two lesions. Only six out of 11 categorically potentially useful clinical variables were statistically significant in differentiating cerebral haemorrhage from infarction. Of the two continuous variables, only diastolic blood pressure achieved significance (table I).

To substantiate the initial results obtained all 13 variables were subjected to stepwise multiple discriminant analysis. With this method five variables were found to be significant for discrimination. The original discriminant equation and a simplified version of the equation (for use in the validation study) are shown in figure 1 . The simplified version was obtained by multiplying each variable by the constant $10 / 3$ in order to achieve more rounded numbers. Figure 2 shows the frequency distribution of the discriminant score when the original equation was used in 164 patients (10 patients were excluded from the original 174 because data were incomplete).

The relation between the discriminant function value and the calculated probability of cerebral haemorrhage for an individual patient is shown in figure 3.

\section{VALIDATION STUDY}

The validation study of the Siriraj stroke score as compared with the diagnosis based on the results of computerised brain scanning of 206 patients with the acute stroke syndrome was performed in 1987-8. Figure 4 shows the distribution of Siriraj stroke scores in patients with haemorrhage and infarction in the validating series. The sensitivities of the score for 
haemorrhage and infarction were $89 \cdot 3 \%$ and $93 \cdot 2 \%$ respectively, with an overall accuracy of $90 \cdot 3 \%$ (table II)

\section{Discussion}

Cerebral haemorrhage is found in $5-10 \%$ of patients with stroke in Europe and America, ${ }^{6}$ but in developing countries the lesion is far commoner, partly because of poorly controlled hypertension. At Siriraj Hospital cerebral haemorrhage accounted for $40-50 \%$ of cases of stroke. ${ }^{7}$ It is well established that the management and prognosis of the acute stroke syndrome vary depending on the diagnosis of haemorrhage or infarction. Hence it is crucial to establish the correct diagnosis as soon as possible.

In 1984 the Guy's Hospital score was developed as a clinical diagnostic tool for intracranial haemorrhage, ${ }^{8}$ and it was later validated by other investigators. ${ }^{9}$ The score for each patient is obtained by calculating several clinical variables with a constant of 12.6 subtracted namely, level of consciousness 24 hours after admission $+7 \cdot 3$ (drowsy) or +14.6 (unrousable); bilateral extensor plantar responses $+7 \cdot 1$; apoplectic onset (defined by the presence of any two of loss of consciousness at onset, headache within two hours, or neck stiffness) $+21 \cdot 9$; diastolic blood pressure after 24 hours $+($ blood pressure $\times 0 \cdot 17)$; aortic and mitral valve disease -4.3 ; cardiac failure $-4 \cdot 3$; cardiomyopathy $-4 \cdot 3$; atrial fibrillation $-4 \cdot 3$; cardiothoracic

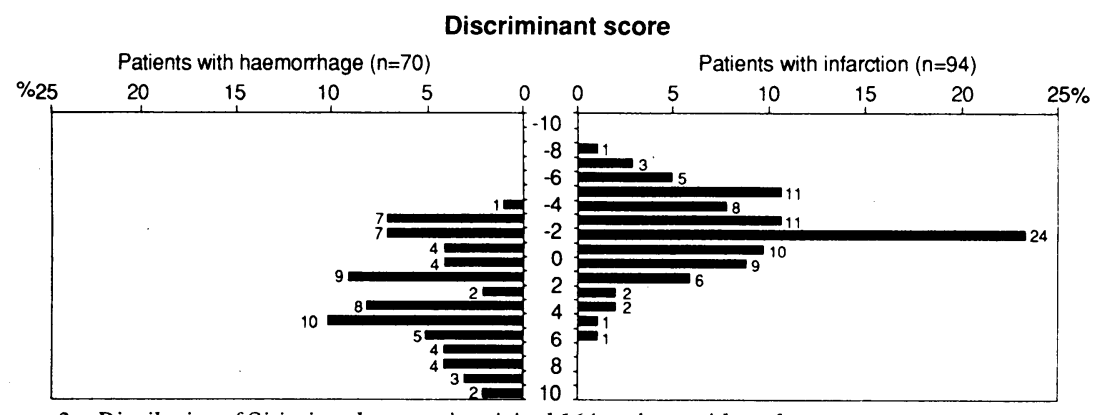

FIG 2-Distribution of Siriraj stroke scores in original 164 patients with stroke

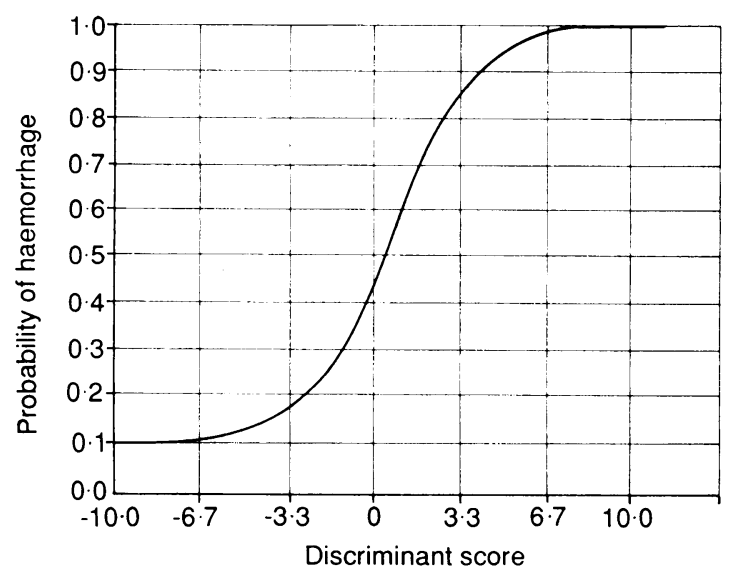

FIG 3-Probability curve of

determined by Siriraj stroke score

Discriminant score

Discriminant score

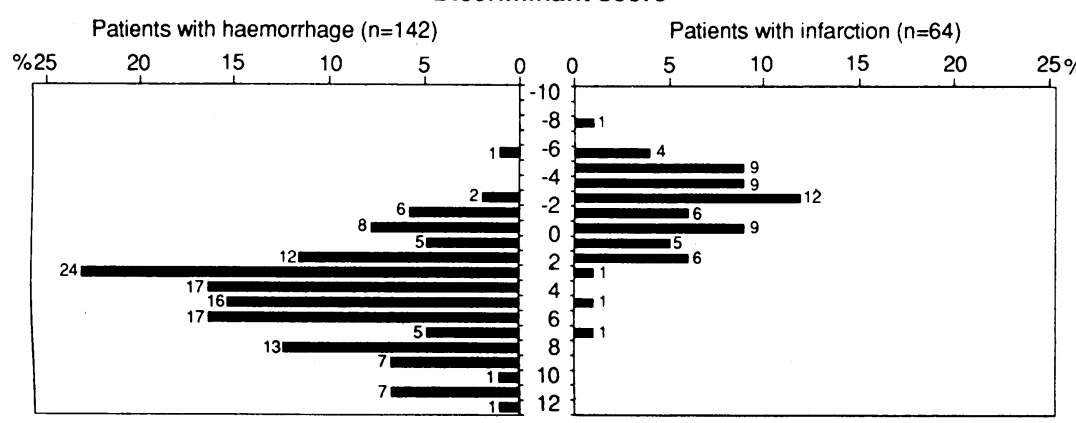

FIG 4-Distribution of Siriraj stroke scores in validating series of 206 patients ratio over 0.5 on chest radiography -4.3 ; myocardial infarction within six months $-4 \cdot 3$; angina, claudication, or diabetes $-3 \cdot 7$; previous transient ischaemic attack or stroke $-6 \cdot 7$; and history of hypertension $-4 \cdot 1$.

Calculating the Guy's Hospital score at the bedside is not easy. The Siriraj stroke score was developed so that only simple calculations would be needed, making it more readily applicable at the bedside. The Guy's Hospital score has been validated and found to have an overall predictive accuracy of $78 \%$ in Oxford and $82 \%$ in London. The Siriraj stroke score showed a $90 \%$ predictive accuracy in acute stroke in a Bangkok community. A supratentorial cerebral haemorrhage usually resulted in a very high score, which was clearly distinguished from the score in infarction. No surprisingly, the Siriraj stroke score also showed higher rate of accuracy in diagnosing stroke owing to the higher prevalence of cerebral haemorrhage. Because of the differing prevalence of acute stroke in different communities it is not possible to make a meaningful comparison between the Guy's Hospital score and the Siriraj stroke score at present.

For the validation study it was evident (fig 4) that the accuracy of the diagnosis would be optimised when the cut off points were set at -1 and 1 . The Siriraj stroke score was thus set at that level to differentiate between haemorrhage and infarction. Since the Siriraj stroke score card was introduced as a diagnostic tool for the acute stroke syndrome in Thailand we believe that at least half of all patients with stroke have been spared a computerised brain scan. The estimated number of new patients with stroke in Thailand a year is 200000 (total population roughly 55 million). Given that a computerised brain scan costs about $£ 70$ per examination, at least $£ 7 \mathrm{~m}$ a year is estimated to have been saved.

The validation study of the Siriraj stroke score, performed two years later, confirmed the overal accuracy of $90 \%$ in acute supratentorial stroke syndrome. As the prevalence of haemorrhagic stroke differs between white and Asian populations, ${ }^{10}$ and the predictive value of any diagnostic score depend greatly on the prevalence of the disease being considered, the Siriraj stroke score may not be applicable transculturally. We suggest that the Siriraj stroke score and the Guy's Hospital score should be compared in both white and Asian populations, in particular with regard to the accuracy and simplicity of the two scores.

The Siriraj stroke score card is now well accepted as a simple screening diagnostic tool at the bedside in rural hospitals in Thailand. The development of the Siriraj stroke score was also intended as an example for the future development of suitable models for diagnostic or prognostic purposes.

1 Viriyavejakul A, Viruchakol M, Utsaha V, Sukondhabhant S. The incidence of neurological diseases in Siriraj Hospital. Siriraj Hospital Gazette of neurological diseases in Siriraj Hospital. Siriraj Hospital Gazette

2 Van Arbin M, De Faire U, Helmers $\mathrm{C}$, et al. Accuracy of bedside diagnosis in stroke. Stroke 1981;12:288-93.

3 Allan CMC. Clinical diagnosis of the acute stroke syndrome. $Q f \mathrm{Med}$ 1983;42:515-23

4 Harrison MJG. Clinical distinction of cerebral haemorrhage and infarction. Postgrad Med f 1980;56:629-32.

5 Schaafsma S. On the differential diagnosis between cerebral hemorrhage and infarction. 7 Neurol Sci 1968;7:83-95.

6 Kurtzke JF. Epidemiology of cerebrovascular disease. In: McDowell F, Caplan LR, eds. Cerebrovascular survey report for the National Institute of Neurological and Communicative Disorders and Stroke. Maryland: Nationa Institute of Health, Public Health Service, 1985:1-34.

7 Viriyavejakul A, Poungvarin N. Internal medicine patient: an analysis of incidence, mortality rate of 27325 admissions. Siriraj Hospital Gazett 1982;34:501-10.

8 Allan CMC. The accurate diagnosis and prognosis of acute stroke. Cambridge: University of Cambridge, 1984. (MD thesis.)

9 Sandercock PAG, Allan CMC, Corston RN, et al. Clinical diagnosis of intracranial haemorrhage using Guy's Hospital score. BMf 1985;291: 1675-7. (Correction 1986:292:173.)

10 Viriyavejakul A. Stroke in Asia: an epidemiological consideration. Clin Neuropharmacol 1990;13(suppl 3):S26-33

(Accepted 25 April 1991) 